\title{
De las imágenes al texto: focalización y uso de recursos anafóricos en relatos de niños y jóvenes
}

\section{From images to text: focusing and anaphoric devices usage in child and young adults' narratives}

\author{
Ana María Borzone ${ }^{1}$ y María Luisa Silva ${ }^{2}$ \\ Centro Interdisciplinario de Investigación en Psicología y Matemática \\ Experimental (CIIPME) \\ Universidad de Buenos Aires, Argentina
}

(Recepción: Octubre 2009 - Aceptación: Junio 2010)

\begin{abstract}
Resumen
Este estudio tiene por objeto analizar el uso de expresiones anafóricas en niños y jóvenes hablantes de español para introducir y mantener la referencia en la producción de un relato a partir de una secuencia de imágenes. Se trata de explorar si los niños y jóvenes estructuran una narrativa autónoma haciendo uso adecuado de mecanismo de correferencia. Participaron cuatro grupos de 5, 8, 11 y 16 años. Los resultados mostraron que el desempeño de todos los grupos es similar en cuanto al predominio en el uso de frases nominales para introducir y reintroducir a los actantes en foco y la elisión para dar continuidad referencial. Pero en los relatos de 5 años se observa una preeminencia de deícticos que denotan la dificultad para producir textos autónomos. Los relatos de los otros grupos muestran un incremento en el dominio de los recursos lingüísticos para cohesionar el texto.
\end{abstract}

Palabras claves: Anáforas, producción infantil; Focalización; Narrativas infantiles; Lenguaje infantil.

\begin{abstract}
This study aims to analyze the use of anaphoric expressions for introducing, re-introducing and maintaining referents in children and teenagers Spanish-speaking narrative productions from a picture book. We try to explore whether they are able to produce an autonomous narrative text by the adequate use of correferential mechanisms. Four groups of children, aged 5, 8, 11 and 16, took part in his study. Results showed that all groups performance is similar with regard to the prevailing use of FN to introduce and re-introduce agent in focus and subjects omissions for referential continuity. But in 5 years old children narratives, the use of deictic forms is very frequent, fact that indicats their difficulty to produce autonomous texts. In the other group's narratives a significant increment in the control over the linguistic cohesive resources was observed.
\end{abstract}

Key words: Anaphors, child production; Focusing; Child narratives; Child Language.

1 Correspondencia a Ana María Borzone. Charcas 2768, Ciudad de Buenos Aires, Argentina, C.P. 1425. Teléfono: (054011) 4961-7722. E-mail: anabor@arnet.com.ar.

2 Correspondencia a María Luisa Silva. Arregui 5449, Ciudad de Buenos Aires, Rep. Argentina, CP 1408. Teléfono: (054011) 4567-4406. E-mail: mluisa@filo.uba.ar. 


\section{Introducción}

Entre el conjunto de habilidades que permiten organizar un discurso se ha reconocido que la posibilidad de vincular cohesivamente los fragmentos depende del dominio evolutivo de los recursos de cohesión, entre los que revisten fundamental importancia las expresiones anafóricas (Chafe, 1974; 1976). En efecto, al producir un discurso, los hablantes introducen una serie compleja de conceptos pero solo algunos de ellos son retomados tanto para desarrollar y dar continuidad al tópico, como para cohesionar el texto. La posibilidad de seleccionar, jerarquizar y vincular expresiones lingüísticas es una operatoria cognitiva compleja que pone de manifiesto la capacidad humana para distinguir y contrastar las entidades que son pertinentes y que, por ello, deben presentarse y mantenerse en primer plano.

Entre los recursos lingüísticos que permiten cohesionar e indicar progresión temática, las expresiones anafóricas han sido objeto de especial interés tanto por su frecuencia en los textos como por las funciones que cumplen en el proceso de producción discursiva (ver revisión en Borzone, 2005 y Borzone y Silva, 2007).

\section{Antecedentes}

Se han considerado a las expresiones anafóricas como ítems que les permiten a los hablantes retomar referentes previamente mencionados para que, al incrementar su accesibilidad y activar los nodos de memoria vinculados a dichos conceptos, el oyente pueda acceder a representaciones de textos coherentes o con escasos espacios de ambigüedad y vaguedad referencial (Gernsbacher, 2000).

En este sentido varios modelos teóricos, desde diferentes disciplinas, coinciden en comprender el uso de expresiones anafóricas como manifestación de la operatoria cognitiva de focalización (Langacker, 1987; Lakoff, 1987; Chafe, 1974; 1976; Givon, 1976; Greene, McKoon \& Ratcliff, 1992). Por medio de este mecanismo los hablantes, ante una cadena compleja de eventos, seleccionan uno o varios actantes que estarán en primer plano, esto es en foco. Resulta fundamental que esta operatoria se realice según restricciones lingüísticas, pues si no se actualiza adecuadamente obstaculiza la posibilidad de que el relato sea comprendido. En efecto, si los oyentes/lectores no distinguen las entidades focales, existirán problemas para articular la conexión causal entre los eventos y, por otra parte, no coincidirá su adjudicación de motivación con la que pretendió realizar el hablante. Pero, en la medida que la conexión se exprese a través de recursos lingüísticos socialmente compartidos y, en este sentido, adecuados, el relato podrá ser comprendido por otros.

Se han realizado diversos estudios sobre el uso de mecanismos de correferencia tanto en niños como en adultos. Si bien los niños desde muy pequeños pueden usar los pronombres (Hernández Pina, 1984), tienen algunas dificultades para emplearlos de manera apropiada en la cadena coreferencial. Aunque antes de entrar a la escuela, los niños pueden usar en narraciones extensas un pronombre para referir a un nombre introducido previamente, se ha reconocido que muchas veces la relación entre el pronombre y su antecedente es ambigua (Hudson y Shapiro, 1997). En este sentido se ha observado que el patrón de empleo de los recursos anafóricos varía con el tipo textual y el conocimiento de dicha variación se adquiere, a su vez, a lo largo del desarrollo (Bronckart, 2006; Hickmann, Kail \& Roland, 1995).

En trabajos previos sobre el uso de expresiones referenciales infantiles se han obtenido resultados contradictorios con respecto a la edad en que los niños dominan el sistema referencial adulto: algunos estudios muestran un dominio temprano (Bamberg, 1986; Power \& Dal Marletto, 1986), otros relativamente tardío (Karmiloff-Smith, 1981; Kail y Hickmann, 1992; Wigglesworth, 1990).

Se ha observado que, si bien los niños de 3 a 5 años producen textos sin anomalías sintácticas, organizan sus textos de manera relativamente poco sofisticada, empleando una estrategia nominal. En esta estrategia predomina el vínculo cohesivo a través de frases nominales completas (estructuras 
del tipo: "un niño", “el niño", "el hijo de los agricultores”) y repetitivas, el pronombre está localmente determinado y con un empleo poco frecuente. A partir de los 5 años los niños comienzan a usar la estrategia pronominal de "sujeto temático" para organizar la narrativa (Karmiloff-Smith, 1981): los niños identifican al protagonista y vuelven a referirse a él mediante el pronombre. En este momento, la pronominalización es consistente a través de toda la narración. Entre los 8 y los 12 años, los pronombres se aplican de manera más flexible, con una estrategia anafórica completa. En este caso, el uso del pronombre no está ligado a un solo personaje. Además, las formas pronominales se emplean para mantener la referencia y las formas nominales para cambios de referencia (Ver revisión en Hudson y Shapiro, 1997).

Bamberg (1987), obtuvo resultados no del todo coincidentes con estas observaciones. En una investigación realizada con niños hablantes de alemán, encontró que los niños de tres años seguían una estrategia de sujeto temático. Este fenómeno ponía en evidencia que los niños manifestaban una sensibilidad más temprana que la observada por Karmiloff Smith (1981) a las restricciones del discurso global.

En este sentido, Wigglesworth (1990) en un estudio sobre la habilidad de los niños para presentar y mantener un personaje de una historia, demostró que el uso de una estrategia de sujeto temático dependía del número de personajes importantes de la historia.

Por su parte, Shapiro y Hudson (1991), exploraron las diferencias en el desarrollo de los recursos anafóricos en función del contexto y del tipo de narración. Los autores evaluaron el desempeño de niños hablantes de inglés, pre-escolares (niños de 4,6 edad promedio) y de primer grado (niños de 6,8 edad promedio) en la producción de narrativas orales a partir de dos secuencias de imágenes: una secuencia que refleja un guión y una secuencia en la que se plantea un conflicto. El análisis del desempeño infantil les permitió identificar 5 (cinco) tipos distintos de estrategias y un uso híbrido en el empleo de los mecanismos de correferencia: 1) La estrategia confusa o indiferenciada; 2) La estrategia general; 3) Una estrategia de sujeto temático; 4) Una estrategia anafórica completa; 5) Una estrategia nominal y 6) Estrategia indeterminada.

Se observó que en las narraciones de los niños más pequeños predominaba la estrategia confusa. Por otra parte, se advirtió que la estrategia de sujeto temático fue más frecuente en la narración del conflicto que en la narración del guión, mientras que en el empleo de la estrategia general se observó la tendencia inversa. Asimismo, aunque los niños de primer grado tenían un mejor desempeño en la producción de historias lingüísticamente complejas, incluso los niños pequeños eran capaces de utilizar recursos de cohesión más avanzados cuando la secuencia de dibujos respondía al formato con conflicto, lo que pone de manifiesto la incidencia del tipo de estructura en el empleo de los mecanismos lingüísticos. En efecto, los autores observaron que la complejidad de los eventos afectaba la coherencia y la cohesión de las narraciones de los niños.

En un estudio posterior Hudson y Shapiro (1997) observaron que la posibilidad de producir textos bien estructurados está ligada a la familiaridad con el tópico. Asimismo advirtieron que los niños mayores eran capaces de usar mecanismos de cohesión más complejos y en situaciones más variadas. Los niños más pequeños utilizaron formas más sofisticadas solo en situaciones de producción cognitivamente menos demandantes.

Por su parte, otros autores han observado que existen factores específicos de las narraciones que afectan el empleo de las expresiones de co-referencia. Así por ejemplo, se ha observado que cuando los niños se refieren al personaje más importante en la historia, usan más frases nominales definidas para la introducción del referente y más pronombres para el mantenimiento de la referencia (ver revisión en Hickman, Kail \& Roland, 1995).

Hickman, Kail \& Roland (1995) investigaron la adecuación informacional de las expresiones referenciales utilizadas por niños franceses de 6, 9 y 11 años en la producción de narraciones a partir del libro de imágenes Frog, where are you? (Mayer, 1969). Las narraciones eran elicitadas en dos situaciones diferentes: en una de ellas, tanto el niño como su interlocutor miraban juntos el libro de imágenes (conocimiento mutuo), mientras que en la segunda condición, el interlocutor tenía 
los ojos vendados (ausencia de conocimiento mutuo). Se observó que la situación de conocimiento mutuo compartido por el niño y la audiencia incidía en el empleo del las expresiones referenciales. Asimismo, los autores advirtieron que las funciones internas de las expresiones de referencia en el discurso se desarrollaban tardíamente, a medida que los niños confiaban más en las relaciones cohesivas del discurso por la ausencia de conocimiento mutuo. Los niños, a partir de los 9 años, producían más pronombres en ausencia del conocimiento mutuo. En las dos condiciones, los niños de 6 años marcaban los límites entre las sucesivas imágenes y los episodios por medio de nominalizaciones. Aunque se encontró un patrón similar en todas las edades en la condición de conocimiento mutuo, el patrón desaparece gradualmente con el aumento de edad en la condición de ausencia del conocimiento mutuo.

Por su parte, Jisa (2000) estudió las producciones narrativas orales de niños de 5, 7 y 10 años y de adultos, hablantes de francés. Jisa identificó un inventario de estructuras referenciales usadas en francés en dos contextos narrativos: en el mantenimiento de un referente sujeto a través de las oraciones y la reintroducciónn de un referente sujeto ya introducido. Entre las estructuras relevadas en el primer contexto, encontró: la repetición de un sustantivo, el empleo de pronombres clíticos, el uso de un pronombre personal o de un pronombre relativo, la presencia de anáforas con reduplicación, de elipsis o de subordinaciones con verbos no conjugados. Para reintroducir un referente, se observaron frases nominales definidas con o sin un pronombre reduplicado y elipsis no finitas (con verbos no conjugados). La autora observó que la variedad de estructuras gramaticales era mayor en el curso del desarrollo y que algunos formas, como por ejemplo la elipsis de sujeto y la subordinación no finita se incrementaban con la edad.

Un estudio similar fue realizado con niños de las mismas edades y con adultos, todos hablantes de español (Kail \& Sánchez y Lopez, 1997). Los investigadores advirtieron que el desempeño de los niños en el empleo de expresiones referenciales se veía afectado tanto por la situación comunicativa (ausencia o presencia de conocimiento muto), como por el desarrollo y las características lingüísticas del español. En efecto, observaron que en la ausencia de conocimiento mutuo eran más comunes las expresiones indefinidas ( un niño), pero que a partir de los 9 años esta situación era común en ambas condiciones de experimentación. Encontraron también que, en la presentación de los personajes, se prefería el orden oracional Verbo-Nombre, y que esto era más común para la presentación del personaje principal en la situación de ausencia de conocimiento mutuo. En cuanto a las restricciones lingüísticas, advirtieron que en español, a diferencia del francés, los niños deben aprender que los pronombres son necesarios, principalmente, en contextos lingüísticos en los que el verbo no es suficiente para identificar el referente sujeto o en contextos con referencias contrastivas.

También en la oralidad, Aguilar (2003) analizó las relaciones anafóricas en las narraciones de niños hablantes de español, de 6 y 12 años producidas a partir del libro de Mayer (1969). El autor observó que los niños más pequeños usaban predominantemente una estrategia de sujeto temático, mientras que los niños mayores empleaban una "estrategia anafórica", es decir, eran capaces de usar frases nominales para cambiar de referencia y pronombres para mantener la cadena referencial.

Por su parte Lapidus Shin y Smith Cairns (2009) en una investigación realizada con seis grupos de niños, jóvenes y adultos hablantes de español cuyas edades eran 7, 9, 11, 13 y 14/15 años y adultos exploraron la preferencia en la selección de pronombres personales (solo consideraron los pronombres de 3 era persona singular) y elisiones en contextos en los que se mantenía y cambiaba la referencia (cambio y mantenimiento de foco). Los resultados de este estudio experimental mostraron que evolutivamente se incrementa la preferencia para seleccionar el pronombre como recurso que permite señalar el cambio de referencia. El cambio más importante se produce entre los 7 y 9 años de edad, etapa en la que se manifiesta mayor sensibilidad al cambio de referencia. Los autores interpretan estos resultados en el marco del modelo generativo, específicamente en relación con las hipótesis sobre las relaciones en la interface sintáctica y las restricciones discursivas.

Como hemos señalado, posiblemente los resultados divergentes respondan a las diferencias entre investigaciones con respecto a la lengua empleada, al tipo y la estructura de los relatos, el modo de presentación (dibujos, secuencia de dibujos, películas y la familiaridad con la historia y la medida 
en que los niños comparten con el entrevistador conocimientos previos (ver revisión en Hickman, 1995).

En varios trabajos los niños y el interlocutor adulto comparten el conocimiento de la historia narrada, por ejemplo están viendo juntos las imágenes (Bamberg, 1987; Karmiloff-Smith, 1981). Se puede pensar que esta situación de conocimiento mutuo puede inducir a los niños a apoyarse más en las ilustraciones que en la organización interna del discurso y, en consecuencia, utilizan más recursos deícticos (Kail \& Sánchez y López, 1997). Además, en los diferentes estudios, aunque se encuentren situaciones comunicativas semejantes, a los niños les solicitan tareas distintas. También varía la extensión y la complejidad de las historias, la cantidad de referentes a ser introducidos, su rol (personaje principal o secundario), la animacidad y/o agentividad de los personajes, factores todos que deben ser atendidos a la hora de sacar conclusiones sobre el desarrollo en el uso de recursos correferenciales.

Por nuestra parte hemos considerado que si las condiciones metodológicas inciden en la sucesión de las etapas descriptas en el uso de las expresiones anafóricas (Karniloff - Smith, 1980; 1986, Jisa, 1986, Hudson y Shapiro,1991 y Shapiro y Hudson, 1996) deberíamos procurar una perspectiva de análisis que contemplara las condiciones de la tarea como constitutivas del fenómeno. En este sentido se adoptó la perspectiva de análisis adoptada por Carroll (1993). En esos trabajos se considera que al producir lenguaje los hablantes generan una estructura conceptual temporaria que se encuentra caracterizada por un grupo específico de opciones pragmáticas, semánticas y sintácticas que guían el proceso de proyección de la información conceptual dentro de formas lingüísticas. La organización de esta estructura conceptual temporaria se relaciona con el tipo de tarea comunicativa que el hablante ejecuta, aunque la decisión de realizar dicha tarea no sea un conocimiento voluntario o consciente. En general cada tarea se resuelve porque el hablante identifica como demanda una pregunta (o quaestio) específica. Así, por ejemplo, si el hablante considera que la narración es mejor forma de presentar una información como respuesta a una tarea asumirá que la pregunta que rige la organización es ¿Qué le ocurrió a X en el tiempo t1, t2, etc.?

De esta forma, en virtud de la tarea y quaestio identificadas el hablante asume diferentes posiciones cognitivas que organizan las relaciones conceptuales y asignan roles preferenciales a ciertos nodos conceptuales. Estas características resultan evidentes en los procesos de selección y disposición de las unidades de información así como en la linearización del discurso. En este sentido, al analizar las relaciones cohesivas indagamos no solo si los niños y jóvenes identifican, distinguen, inhiben o mantienen los actantes focales sino también cómo esta operatoria se conforma en virtud de la tarea que los niños han reconocido.

Por ello, en esta investigación se procura explorar si existe relación entre la posibilidad de que niños y jóvenes identifiquen la demanda de la tarea y estructuren una narrativa autónoma con el uso adecuado de mecanismos de correferencia.

\section{Método}

\section{Participantes}

Participaron de este estudio sesenta (60) niños y jóvenes de NSE Medio que asistían a una misma institución educativa ubicada en la Ciudad de Buenos Aires, Rep. Argentina. Se seleccionó esa institución pues posee los tres niveles educativos: preescolar, primario y medio. La categorización de la población se realizó en base a un grupo de criterios que consideran los niveles educativos y las ocupaciones que ejercen sus padres (Sautú, 1992). En este grupo de niños se tuvo en cuenta que, al menos, uno de sus padres fuera profesional con educación universitaria o terciaria.

Los niños fueron segmentados en tres grupos etarios, G1: preescolares (promedio de edad: 5,7 rangos 5,0-5,11); G2: tercer año de la Escuela Básica (promedio de edad: 8,5 rango 8,0- 8, 9) y G3: 6 año de la Escuela Básica(promedio de edad: 11, 3 rango 11,0- 11,8 ). Los jóvenes conformaron el G4: 4 año de la Escuela Media (promedio de edad: 16, 8 rango 16, 3- 16, 11). Cada grupo está 
compuesto por 15 sujetos. Ninguno de ellos presenta síntomas de déficit lingüístico otras patologías que afecten su competencia comunicativa. Todos los niños son hablantes monolingües y eficientes de español.

\section{Material}

Para realizar este estudio se elicitaron relatos orales a partir de una secuencia de 16 imágenes carentes de texto. Las imágenes constituían un relato de ficción de 1 Escena o Marco y 4 (cuatro) episodios completos. El relato que sirvió de base para elaborar la secuencia de ilustraciones es "El mago bueno y la bruja mala" (Rawson, 1981). En el relato se presenta el conflicto que surge a partir de que una bruja hechiza a la hija de unos agricultores y la transforma en perro. Los agricultores tratan de atrapar a la bruja, pero esta escapa. Recurren a varias personas para solucionar el problema y estos les indican que un hechicero puede romper el encanto. El hechicero al observar los sucesos en su bola de cristal, castiga a la bruja y rompe el hechizo. Todos le agradecen al hechicero su intervención.

El cuento que muestran las imágenes consiste en una imagen en la que se presentan los protagonistas y el contexto físico en el que ocurrirán los acontecimientos (Escena o Marco) y 4 (cuatro) episodios, en los que ocurren diferentes eventos conectados causalmente entre sí a partir de la actividad de los personajes (Stein y Glenn, 1979).

Cada episodio consiste de: evento inicial (imagen en la que se presenta la acción (es), evento(s) o suceso(s) que causa(n) o inicia(n) una respuesta en el protagonista), respuesta interna (imagen en la que se puede inferir cierto estado emocional, cognitivo y/o propósito del protagonista), intento (imagen que presenta acción(es) o evento(s) para lograr el propósito del protagonista), consecuencia directa (imagen que ilustra la/s Acción/es o evento/s que marcan el éxito o el fracaso del protagonista) y reacción (imagen que presenta la/s emoción, cognición, acción o estado final que expresa los sentimientos del protagonista acerca del logro o fracaso del propósito).

\section{Recolección de información empírica}

En entrevistas individuales se presentó a los sujetos la secuencia de ilustraciones. Se les comentó que la secuencia de imágenes narraba una historia, luego se presentaron los personajes. Los niños examinaban toda la secuencia de imágenes, sin límite de tiempo y, luego, se les solicitaba que la relataran oralmente. Los sujetos contaron con la presencia de las ilustraciones durante la narración.

Todos los relatos producidos fueron grabados y luego transcriptos en forma ortográfica.

\section{Análisis de la información empírica}

Se analizaron las versiones transcriptas de los relatos.

El estudio considera dos aspectos del desarrollo narrativo relacionados entre sí. Por una parte la posibilidad de elaborar narrativas autónomas a partir de imágenes y en segundo término la posibilidad de cohesionar adecuadamente las menciones de los actantes. Para el primer aspecto se consideraron como indicadores la Extensión de los textos, medida en cantidad de palabras; la Extensión de los textos en Ut modificada ${ }^{3}$ y la mención completa de los Episodios. Estos indicadores consideran la fluidez para elaborar una narrativa coherente y completa. Por otro lado también se considero la cantidad de Expresiones Deícticas que refieren a las imágenes (por ej. los adverbios: acá, ahí, o los pronombres: esta, esa, con referencia a las imágenes), pues permiten observar el grado de dependencia de las narrativas con la secuencia de imágenes y con el conocimiento compartido (Kail y Sanchez Lopez, 1997).

3 Se consideró como UT modificada a la unidad de análisis inicialmente planteada por Hunt (1965) y en español adaptada por Véliz (1988). Pero, en virtud de las críticas realizadas para la implementación de esta unidad en español por Rodríguez Fonseca (1999) y Silva, Sánchez Abchi y Borzone (2009), se estimó conveniente considerar solo como subordinaciones aquellas relaciones de dependencia sintáctica muy estrecha, es decir las cláusulas relativas de modificador de actante y las completivas de verbo no finito. Todas las demás subordinaciones se consideraron UT independientes. 
Para el segundo aspecto se consideraron, en cada relato, las expresiones que eran los sujetos gramaticales de los enunciados. Se tuvieron en cuenta las frases nominales (Fns.) (construcciones sintácticas constituidas por un sustantivo núcleo y, por lo menos, un modificador), las elisiones de frases nominales con función anafórica (els.), los pronombres personales con función anafórica (prons.) y otros ítemes léxicos con función anafórica (otrls.) (el uso de expresiones sin determinantes, por ejemplo: "todos").

Dado que debíamos evaluar si los niños usaban adecuadamente los mecanismos anafóricos para indicar el cambio de foco y de esta forma presentar adecuadamente a los actantes.

Inicialmente se consideraron sólo las expresiones en posición de sujeto agente y se tomó la codificación de Schneider y Dubé (1997) adaptada al español. Cada expresión referencial para presentar un personaje o para mantener la referencia en cada historia fue clasificada como "adecuada o inadecuada" de acuerdo a los siguientes criterios:

a) Una expresión referencial usada para introducir un referente por primera vez se consideró adecuada si se utilizaba un nombre propio o una frase nominal con artículo indefinido. Las expresiones de presentación de referente con artículo definido, sin artículo alguno, los pronombres o las elipsis fueron codificadas como inadecuadas.

b) Las expresiones para reintroducir un referente fueron consideradas adecuadas si se referían al referente con claridad. Las elipsis ambiguas, los pronombres ambiguos o el uso de un ítem léxico diferente fueron codificados como inadecuados.

Además se elaboró una cadena de progresión de actantes para considerar si las menciones de los niños resultaban adecuadas al planteo del texto original. Para elaborar tal cadena se consideraron las actividades de los personajes (actantes) en relación a los eventos y al cambio de foco según lo presentaba el relato original. Se elaboró la siguiente cadena de intervención y progresión de actantes:

1. familia de la nena; 2.Nena / Bruja; 3. Bruja; 4. padres / bruja;5. padres / nena; 6. padres/ vecinos;7. padres/ mago; 8. mago/ bruja; 9. mago/ nena; 10. nena/ padres/ mago.

Esta cadena nos permitió evaluar los usos de cada uno de los ítemes lingüísticos (Fns, els., prons. y otrls.) en relación a su adecuación e inadecuación.

El procesamiento estadístico de los datos nos permitió obtener medidas de Medias y Frecuencias de aparición para los usos adecuados e inadecuados de Fns. y elis. Para el uso de pronombres con función anafórica se consideraron únicamente las Frecuencias. Esta distinción en el procesamiento estadístico se justifica por el hecho de que el español es una lengua de sujeto nulo (pro-dop), es decir que la concordancia verbal habilita la omisión de sujetos. Esta característica tipológica hace que los hablantes prefieran como mecanismo de cohesión la elisión frente a la mención de pronombres anafóricos en la posición de sujeto gramatical. En cambio, en otras posiciones, la mención de pronombres personales es obligatoria. Este fenómeno nos llevó a considerar la mención de pronombres en otras posiciones sintácticas, por lo que en el análisis se relevo también la mención de Pronombres en otras posiciones sintácticas y se tabularon las Frecuencias de uso.

Finalmente se realizó un análisis cualitativo del uso de las diferentes formas de cohesión anafórica.

\section{Resultados}

Los resultados de este estudio muestran que los niños progresan en el dominio de todas las variables analizadas. En la tabla 1 se presenta el análisis de las variables que atienden a la posibilidad de elaborar narrativas autónomas. 


\section{Informe}

Tabla 1: Indicadores de narrativa autónoma: Medias y desvíos según edades

\begin{tabular}{|c|c|c|c|c|c|}
\hline $\begin{array}{c}\text { Edad en } \\
\text { años, meses }\end{array}$ & Medidas & $\begin{array}{c}\text { Extension en can- } \\
\text { tidad de palabras } \\
\text { totales }\end{array}$ & $\begin{array}{c}\text { Extensión del } \\
\text { texto en UT modi- } \\
\text { ficada }\end{array}$ & $\begin{array}{c}\text { Cantidad de deíc- } \\
\text { ticos que refieren a } \\
\text { imágenes }\end{array}$ & $\begin{array}{c}\text { Cantidad de } \\
\text { episodios } \\
\text { referidos }\end{array}$ \\
\hline 5.00 & Media & 140.87 & 20.27 & 7.73 & 1.60 \\
\hline & Desv. típ. & 70.630 & 6.364 & 5.574 & 1.242 \\
\hline 8.00 & Media & 237.87 & 36.53 & 1.07 & 3.00 \\
\hline & Desv. típ. & 64.666 & 9.657 & 2.052 & 1.134 \\
\hline 11.00 & Media & 249.33 & 39.40 & .13 & 2.80 \\
\hline & Desv. típ. & 100.820 & 13.953 & .352 & .941 \\
\hline 16.00 & Media & 275.40 & 36.80 & .20020 & 3.33 \\
\hline & Desv. típ. & 123.261 & 16.562 & .561 & .900 \\
\hline
\end{tabular}

Del análisis comparativo de los valores de las $\mu$ se observa un progresivo incremento en 2 (dos) indicadores de fluidez en la elaboración de narrativa autónoma (Extensión en cantidad de palabras: 5.: $140.87 ; 8: 237.87 ; 11: 249.33$ y 16: 275.4 y Extensión del texto en UT modificada5.: 20.27; 8: 36.53; 11: 39.4 y 16: 36.8) En Cantidad de episodios referidos se observa un incremento notable entre los 5 y los 8 años (De 1.6 episodios en 5 a 3.00 en 8 años) y luego cierta estabilidad en una $\mu$ de 3 episodios (11: 2.8 y 16:3.33). Se observa simultáneamente una disminución notable en los usos de deícticos que refieren a las imágenes (Cantidad de deícticos que refieren a imágenes5.: 7.73; 8: 1.07; $11: 0.13$ y $16: 0.20)$.

Pareciera que los niños progresan evolutivamente en su capacidad de producir narrativas más extensas, sintácticamente más complejas, con mayor cantidad de episodios y que no descansan en las imágenes para ser comprendidas.

Resulta llamativo en todos los indicadores mencionados la diferencia en el incremento que se observa entre los 5 y 8 años, no solo en Cantidad de palabras sino también en la Unidades sintácticas consideradas y en episodios completos narrados.

Con el objetivo de explorar si las diferencias resultan estadísticamente significativas se realizó un análisis de varianza (MANOVA) con un factor (edad en años). La prueba post hoc de comparaciones múltiples nos permitió observar los siguientes valores: Extensión del texto en cantidad de palabras: 5 a 8 (df -97.00 p =0.036); 8 a 11 (df $-11.47 \mathrm{p}=1.00)$; 11 a 16 (df - $26.07 \mathrm{p}=1.00)$; Extensión del texto en UT modificada: 5 a 8 (df $-16.27 \mathrm{p}=0.004$ ); 8 a 11 (df $2.87 \mathrm{p}=1.00$ ); 11 a 16 ( df $2.60 \mathrm{p}=$ 1.00); Cantidad de episodios referidos: 5 a 8 (df $-1.40 \mathrm{p}=0.004$ ); 8 a 11 (df $0.20 \mathrm{p}=1.00$ ); 11 a 16 (df $-0.537 \mathrm{p}=1.00$ ) y Cantidad de deiçticos que refieren a imágenes $5 \mathrm{a} 8$ (df $6.67 \mathrm{p}=0.000$ ); 8 a 11 (df $0.93 \mathrm{p}=1.00) ; 11$ a 16 ( df $-0.08 \mathrm{p}=1.00)$, en todos los casos siendo $\mathrm{p}=0.05$ ).

Es decir, en todos los indicadores de estructuración de narrativa autónoma las diferencias significativas se producen entre el grupo de 5 y el de 8 años. Podemos suponer que este fenómeno puede deberse a la conjunción de la incidencia del factor evolutivo y la incidencia de las prácticas escolares, ya que la tarea evaluada es una tarea curricular en los primeros niveles educativos.

Por su parte el análisis de los indicadores que nos permiten considerar la adecuación en el uso de los recursos referenciales por los diferentes grupos de niños, manifiesta un paulatino incremento en el dominio de las elecciones adecuadas (Tabla 2). 
Tabla 2: Indicadores de uso adecuado de recursos referenciales:

Medias y desvíos según edades

\begin{tabular}{|c|c|c|c|c|c|c|c|}
\hline $\begin{array}{c}\text { Edad en } \\
\text { años, } \\
\text { meses }\end{array}$ & Medidas & $\begin{array}{c}\text { Cantidad } \\
\text { de FN } \\
\text { correctas }\end{array}$ & $\begin{array}{c}\text { Cantidad } \\
\text { de FN in- } \\
\text { correctas }\end{array}$ & $\begin{array}{c}\text { Cantidad de } \\
\text { elisiones de } \\
\text { FN correctas }\end{array}$ & $\begin{array}{c}\text { Cantidad } \\
\text { de elisiones } \\
\text { de FN inco- } \\
\text { rrectas }\end{array}$ & $\begin{array}{c}\text { Cantidad de } \\
\text { otros ítemes } \\
\text { léxicos } \\
\text { correctos }\end{array}$ & $\begin{array}{c}\text { Cantidad de } \\
\text { otros ítemes } \\
\text { léxicos inco- } \\
\text { rrectos }\end{array}$ \\
\hline 5.00 & Media & 7.20 & 2.87 & 4.13 & 4.93 & .00 & .00 \\
\hline & Desv. típ. & 4.280 & 1.356 & 4.307 & 3.900 & .000 & .000 \\
\hline 8.00 & Media & 15.40 & .60 & 12.13 & 6.93 & .87 & .00 \\
\hline & Desv. típ. & 4.733 & .910 & 4.486 & 6.850 & 1.060 & .000 \\
\hline 11.00 & Media & 16.93 & .60 & 14.20 & 1.87 & .67 & .00 \\
\hline & Desv. típ. & 7.592 & .986 & 5.401 & 1.727 & 1.799 & .000 \\
\hline 16.00 & Media & 16.73 & .00 & 15.93 & .80 & 1.47 & .00 \\
\hline & Desv. típ. & 7.658 & .000 & 7.750 & 1.265 & 1.685 & .000 \\
\hline
\end{tabular}

Como puede observarse, en Tabla 2, si bien en todos los grupos existe un predominio en el uso de Frases nominales y Elisiones de Fns. para introducir y reintroducir actantes, en los grupos de edades más avanzadas comienza a observarse un incremento en el uso de pronombres. Por otro lado se observa, paralelamente, una disminución en los usos inadecuados, tanto de Fns. como de elisiones.

Con el objeto de explorar si las diferencias resultan estadísticamente significativas se realizó un análisis de varianza (MANOVA) con un factor (edad en años). La prueba post hoc de comparaciones múltiples nos permitió observar que en el uso adecuado de Fns y de elisiones las diferencias significativas se producen entre el grupo de 5 y 8 años (Cantidad de Fns correctas: 5 a8 (df: $-8.20 \mathrm{p}=$ 0.004); 8 a 11 (df: $-1.53 \mathrm{p}=1.00$ ); 11 a 16 (df: $0.20 \mathrm{p}=1.00$ ); Cantidad de elisiones correctas: 5 a 8 (df: $-8.00 \mathrm{p}=0.002) ; 8$ a $11(\mathrm{df}-2.07 \mathrm{p}=1.00) ; 11$ a $16(\mathrm{df}-1.73 \mathrm{p}=1.00)$ siendo siendo $\mathrm{p}=0.05)$. En los otros indicadores de usos adecuados no se observa esa estimación (Cantidad de pronombres adecuados: 5 a 8 (df - $0.93 \mathrm{p}=0.284) ; 8$ a $11(\mathrm{df}-0.87 \mathrm{p}=0.389) ; 11$ a 16 ( df $0.20 \mathrm{p}=1.00)$ y Cantidad de otros ítemes léxicos usados adecuadamente: 5 a 8 (df - $0.87 \mathrm{p}=0.494$ ); 8 a 11 (df 0.20 $\mathrm{p}=1.00) ; 11$ a $16(\mathrm{df}-0.8 \mathrm{p}=0.648)$ siendo $\mathrm{p}=0.05)$.

Los resultados parecen avalar la hipótesis acerca del cambio evolutivo que se observa entre niños de 5 y de 8 años en relación la estructuración de narrativas autónomas y la consolidación de estrategias adecuadas en el uso de recursos anafóricos.

Consideramos que la diferencia entre los resultados del uso adecuado de Fns. y de elisiones con respecto al uso adecuado de pronombres y de otros itemes léxicos esta ocasionada por la escasa frecuencia de uso de estos recursos anafóricos. No obstante consideramos que dicha tendencia nos está revelando más que una característica evolutiva el dominio de un rasgo distintivo del español: preferir el uso de frases nominales o elisiones para la posición de sujeto gramatical en lugar de pronombres personales.

Con el propósito de explorar esta hipótesis comparamos la frecuencia en el uso de los pronombres personales en posición sujeto frente a otras posiciones sintácticas. Para ello no solo confrontamos las frecuencias de aparición de pronombres personales en caso nominativo (por ej.: el, ella, Usted, etc.) en diferentes posiciones sintácticas sino que además confrontamos estas frecuencias con las de aparición de pronombres personales en otros casos (por ej. dativo: le; acusativo: lo, la; complemento: cuyo). Los resultados de esta indagación se presentan en las Tablas 3, 4 y 5. 
Tabla 3: Frecuencia relativa de uso adecuado de pronombres personales en nominativo en posición sujeto gramatical

\begin{tabular}{|c|c|c|c|c|}
\hline $\begin{array}{c}\text { Cantidad de pronombres/ } \\
\text { Grupos de edad }\end{array}$ & 0 & $1-2$ & 3 & +3 \\
\hline 5.00 & 100 & - & & \\
\hline 8 & 60 & 26.7 & 6.7 & 6.7 \\
\hline 11 & 26.7 & 46.3 & 13.3 & 13.4 \\
\hline 16 & 26.7 & 53.4 & 6.7 & 13.4 \\
\hline
\end{tabular}

Tabla 4: Frecuencia relativa de uso adecuado de pronombres personales en nominativo en otras posiciones sintácticas

\begin{tabular}{|c|c|c|c|c|}
\hline $\begin{array}{c}\text { Cantidad de pronombres/ } \\
\text { Grupos de edad }\end{array}$ & 0 & $1-2$ & 3 & +3 \\
\hline 5.00 & 86.7 & 13.15 & & \\
\hline 8 & 80 & 13.3 & 6.7 & \\
\hline 11 & 93.3 & 6.7 & & \\
\hline 16 & 66.7 & 26.7 & & 6.7 \\
\hline
\end{tabular}

Tabla 5: Frecuencia relativa de uso adecuado de otros pronombres en otras posiciones sintácticas

\begin{tabular}{|c|c|c|c|}
\hline $\begin{array}{c}\text { Cantidad de pronombres/ } \\
\text { Grupos de edad }\end{array}$ & $1-6$ & $7-10$ & +11 \\
\hline 5.00 & 86.7 & 13.4 & \\
\hline 8 & 33.4 & 33.0 & 34.6 \\
\hline 11 & 13.4 & 40 & 47.5 \\
\hline 16 & 33.3 & 28.4 & 39.2 \\
\hline
\end{tabular}

Como se puede inferir de la comparación de frecuencias la hipótesis acerca de que la escasez de pronombres personales en posición sujeto se debe a características del español, en tanto lengua que prefiere las elisiones para reintroducir actantes, pareciera confirmarse. En efecto como la preeminencia de ausencia de pronombre en la posición sintáctica sujeto así como en otras posiciones frente a la preponderancia de uso de pronombres en otras posiciones sintácticas pareciera confirmarlo. Por otro lado debemos destacar que el manejo de los casos pronominales es un rasgo morfológico más complejo que el manejo del caso nominativo, por lo que no resulta adecuado aducir causas evolutivas para explicar este hecho.

\section{Posicionamiento cognitivo, establecimiento del foco y uso de recursos lingüísticos en los distinto grupos de edad}

Los datos obtenidos en el presente estudio permiten inferir que los niños más pequeños adoptan una perspectiva cognitiva que refleja que están descansando sobre el conocimiento que proporcionan las imágenes en tanto estímulo compartido con el observador.

En este sentido, en tanto la historia supone cambios frecuentes de actantes en primer plano (ver análisis en Metodología) la operatoria de focalización requiere un uso preciso de los recursos anafóricos que no se observa en los relatos de los niños de 5 años. En efecto sus producciones se caracterizan por una preeminencia de términos deícticos que denotan la imposibilidad de constituir 
narrativas autónomas. En este sentido la actividad de focalización está dada por el gesto deíctico de señalar con el índice el personaje en primer plano. De ahí que los relatos producidos por estos niños, si se evalúan como textos autónomos, poseen espacios de vaguedad y ambigüedad referencial que dificultan la comprensión del relato. En estos relatos se observa que los personajes se introducen con estos términos y/o con frases indeterminadas. Las menciones posteriores de los personajes se realizan con frases determinadas. Los pronombres objetivos y el uso de pronombres de desinencia verbal permiten retomar a los actantes pero no se utilizan, salvo en algunos casos, pronombres personales en función nominal ni otras expresiones anafóricas para retomar relaciones entre los participantes.

Se puede pensar que el entorno y el tipo de tarea condicionaron a los niños para que anclaran el discurso en las imágenes, a través de las cuales se podría resolver la ambigüedad mencionada. De hecho el uso de las expresiones anafóricas no se asemeja a las del formato de un texto escrito sino a un relato híbrido entre una versión conversacional y un relato.

Así por ejemplo, una niña de 5 años enuncia, al observar las primeras imágenes

“Acá ((gesto deíctico)) van a plantar una plantita. Después ((gesto deíctico)) hay una bruja y un ratón. Acá ((gesto deíctico)) la nena la viene a espiar. Acá ((gesto deíctico)) la bruja la convierte en gato o perro. Y acá, acá, acá ((gesto deíctico)) le están diciendo que por que le hizo eso a la nena" [5, sujeto 4].

Pero cabe señalar que algunos relatos de estos niños de 5 años pueden asimilarse a los de los grupos mayores, en tanto manifiestan las características preponderantes en esos grupos. Esta observación nos indica que dentro de un grupo etario, si bien se identifica una tendencia, pueden encontrarse también casos de niños que adoptan otra posición cognitiva para resolver la tarea.

Así otro niño de 5 años relata al observar las imágenes posteriores al hechizo:

"Y el papá se enojo mucho. Entonces la llevaron a la casa del brujo bueno que era muy buen amigo de ellos [...].Después hizo un experimento para que se transformara en una nena como fue antes" [5, sujeto 9].

Los niños mayores y los jóvenes, en cambio, resultan un grupo más homogéneo y puede inferirse, a partir del uso de recursos, que han adoptado una posición de narrador tradicional para resolver la tarea. En efecto, el análisis de los relatos producidos por los niños mayores y los jóvenes muestra un salto cualitativo en su desempeño como narradores especialmente entre el grupo de $5 \mathrm{y}$ el de 8 años.

En este sentido se observa que los relatos de los niños de 8 años presentan características formales semejantes a las que se atribuyen a un relato tradicional. A diferencia del grupo de 5 años, no se observa, salvo en contadas ocasiones el uso de términos deícticos, indicio de que los sujetos abordan la tarea como la ejecución de un relato autónomo, no basado en conocimiento compartido. La primera introducción de los referentes se realiza a partir de frases nominales indeterminadas con cláusulas relativas que a menudo se incorporan en la frase de apertura, por ejemplo:. "Había una vez un papá, una nena y una mamá que estaban haciendo la cosecha” [8, sujeto 17].

Los referentes se mantienen y reintroducen con frases nominales determinadas. Este uso predominante de frases nominales parece responder al hecho de que la historia está formada por varios episodios en los que varía la preeminencia de los actantes. Cabe señalar que, pese al cambio de actante, en los relatos se conserva la relación causal entre episodios porque los narradores seleccionan adecuadamente el evento que organiza el episodio.

Así un niño de 8 años enuncia al narrar el episodio que causo el conflicto:

"[ ...] estaba una bruja durmiendo y se había comido todas las manzanas que había dejado en la canastita. Y la nena le dice:" Qué hace usted acá. Usted se comió todos mis frutos" "Sí, pero ahora te voy a hacer un hechizo". Le hizo un hechizo y la nena quedó como un perrito" [8, sujeto 20]. En este fragmento se pone de manifiesto que los narradores seleccionan, de las imágenes, los eventos 
que están vinculados causalmente: la bruja se comió las manzanas de la nena, la nena la reta, la bruja la castiga con su hechizo.

Entre otros aspectos, la selección adecuada de eventos permite no solo conservar las relaciones cohesivas sino que tenor, también otorga coherencia al relato. En efecto en el fragmento trascripto hay elipsis y usos de frases nominales pero en la medida en que resultan estratégicamente dispuestas no dan lugar a ambigüedades.

No obstante hay algunos casos en los que se observa ambigüedad, por ejemplo, en el siguiente relato que hace un niño de 8 años de la secuencia de ruptura del hechizo y castigo a la bruja:

"Después está el señor, la mamá y el papá y le dice que le puede curar a mi hija señor mago de este hechizo." Usted señora bruja se va a quedar acá encerrada hasta que yo termine el hechizo para poner a la nena bien [... ] cuidado, cuidado se incendia, va a explotar. Tengo que tratar de salir de acá, tengo que ir corriendo, de pronto la llama está al lado de ella. Eh, gritan, nos salvamos y saludan al mago". [8, sujeto 25].

En la mayor parte de estos casos la ambigüedad resulta de la inclusión de discurso directo sin la previa aparición de verbos de "decir", sin la mención de los actantes que profieren esos dichos y el uso de frases nominales, genéricas y por lo tanto, ambiguas, por ejemplo utilizar "el señor" en lugar de "el brujo", "el mago" o "el hechicero",

Tanto en el grupo de 8, como en el de 11 y 16 años, los narradores recurren, además de frases nominales, a una variedad de expresiones anafóricas: pronombres clíticos ("Y cuando le iba a pegar ya era tarde"), pronombre personales ("la nena le dice que ella se comió todas las manzanas"), pronombres posesivos ("una nena que iba tranquila con sus padres llevando manzanas"), hiperónimos ("Había una vez tres personas"), incluso sustantivos de referencia única ("Lucía se va a plantar los").

La posición narrativa de estos sujetos se manifiesta también en el uso de frases de apertura y cierre ("Había una vez", "Y el cuento terminó.. todos contentos"), marcadores de sucesión temporal ("después..."), índices de verosimilitud (El mago se fijó en la bola. Vio la cara de la bruja. Dijo:"Veremos qué puedo hacer". la bruja le sacó la lengua), inserción de discurso referido y directo, rasgos descritos como característicos del relato tradicional.

Si analizamos el desempeño del grupo de niños de 11 y de 16 años en el uso de las expresiones anafóricas que permiten reintroducir los referentes observamos que se caracteriza porque manifiesta el empleo adecuado de las relaciones cohesivas, tanto las de índole gramatical (pronominalización en variados casos: nominalizaciones -"el padre, él"; "la bruja, ella"-, clíticos -“le dice”- y posesivos - "su hija" -; y elisiones) así como de relaciones cohesivas léxicas (sinonimias - "todo el mundo", "gente"; "el hechizo", "el maleficio"; "el padre, el papá”, etc. - hiperonimia -"las manzanas, la fruta" - hiponimia - "una familia de granjeros, el padre, la madre, los padres"; etc.,). Se observa también que se respetan los límites de procesamiento que plantea la distancia en enunciados entre expresión referencial y expresión anafórica.

Otro rasgo característico de este grupo es el uso de expresiones anafóricas gramaticales complejas ("la cual", "lo cual", "el que"), uso que en algunos casos resulta de baja aceptabilidad ("Una familia de campesinos llega a su casa del trabajo y el hijo o la hija se encuentra en el granero a una bruja, la cual estuvo comiendo y durmiendo en el granero" [16, sujeto 47].)

Un aspecto interesante a señalar de desempeño de los niños en todos los grupos, es el uso de pronombres y frases nominales o de elisiones y frases nominales a través de las cuales el hablante evita un probable problema comunicativo: la posibilidad de que el oyente no comprenda la selección de referentes en forma adecuada.

Así por ejemplo en el grupo de 5 una niña dice:

“A la mañana, él corría, corría, el nenito”. [5, sujeto 9] 
En el grupo de 8

"Habia una vez una nena que iba con sus padres llevando manzanas. Luego el padre escuchó unos ruidos en la cabaña. Le dijo a la nena que vaya a ver qué sucedía. Ella, la nena, se asomó por la puerta" [8, sujeto 18]

En el grupo de 11

"Entonces empieza a hacer un antídoto, el mago empieza a hacer un antídoto para curar al chico. Después, la bruja, ella aparece por su bola de cristal, por la bola de cristal del mago”. [11, sujeto 49]

En síntesis, estos resultados permiten suponer que la progresión en el desarrollo no se restringe al dominio de reglas gramaticales para el uso adecuado de las expresiones anafóricas sino que requiere también del dominio de la coordinación de recursos lingüísticos específicos que actualizan la operatoria de focalización.

\section{Discusión}

Los datos obtenidos en este trabajo muestran que si bien hay diferencias entre los grupos, en tanto se observa un incremento en el dominio de los recursos anafóricos, el desempeño pareciera estar condicionado por el contexto de la tarea de relato y por las características gramaticales y discursivas de la lengua.

El uso de las expresiones anafóricas en los niños de 5 de este estudio responde a grandes rasgos a las características de la estrategia nominal (Shapiro \& Hudson, 1997). Sin embargo el hecho de que el español sea una lengua pro-drop habilita desde edades tempranas el uso de elisiones en la posición de sujeto gramatical como la forma más frecuente de dar continuidad referencial.

No se identifican en este grupo de edad, ni en los otros grupos, casos de uso de una estrategia de sujeto temático (Karmiloff-Smith, 1986). La diferencia entre estas observaciones y de las realizadas en estudios previos (Borzone \& Granato, 1995; Aguilar, 2003) en las que se halló el uso de esa estrategia puede deberse a diferencias metodológicas. Tanto en los estudios de de Borzone y Granato (1995) que elicitaron relatos de experiencia personal como de Aguilar (2003) que elicitó narrativas a partir de una secuencia de imágenes, el foco de las historias se ubica en un único actante. Nuestra investigación, por el contrario, presenta cambios frecuentes de protagonista en foco, hecho que no promueve la aparición de la estrategia de sujeto temático.

En este sentido Wigglesworth (1990) también señaló que el uso de esa estrategia dependía del número de protagonistas de la historia.

Por su parte, si atendemos a las diferencias evolutivas en el uso de expresiones deícticas se observan resultados similares a los obtenidos por Kail y Sánchez y López (1997) Este uso, sumado a la presencia frecuente de frases nominales inadecuadas y elisiones inadecuadas da lugar en los relatos de los niños a segmentos de comprensión ambigua, que responde al anclaje en las imágenes.

Si bien en un estudio previo se ha señalado que el mayor cambio evolutivo en el uso de expresiones anafóricas se produce entre los 7 y 9 años, en español, el cambio observado en este trabajo entre el desempeño de los niños de 5 y 8 se encontraría dentro del rango de edad descripto por Lapidus Shin \& Smith Cairns (2009).

Por otro lado al considerar el desempeño de los grupos de mayor edad se identifica un paulatino incremento en la frecuencia y variedad de los recursos anafóricos utilizados. Vistos en su conjunto los resultados de este trabajo parecen indicar que la operatoria cognitiva de focalización no responde a una habilidad comunicativa general sino que se va conformando en las interacciones sociales que proporcionan las estructuras características de la lengua. 
Las expresiones anafóricas comienzan aparecen en el habla infantil en forma esporádica en contextos formulaicos con un rango de funciones discursivas restringido. A medida que los niños y jóvenes adquieren con la edad y con el incremento de la experiencia lingüística un mayor dominio del léxico, de la sintaxis y de las formas discursivas, se va incrementando la variedad y adecuación en el uso de expresiones anafóricas que se van engarzando estratégicamente hasta alcanzar una textura sin ambigüedades.

\section{Referencias}

Aguilar, C. (2003). Análisis de frecuencias de construcciones anafóricas en narraciones infantiles, Estudios de Lingüistica aplicada, 22 (38), 33-43.

Bamberg, M.G.W. (1986). A functional approach to the acquisition of anaphoric relationships. Linguistics. 24, 227-284.

Bamberg, M.G.W. (1987) The acquisition of Narratives Learning to Use Language. Berlin: Mouton de Gruyter.

Borzone, A.M. ; Silva, M.L.; Sanchez Abchi, V. (2009). Subordinated Clauses Usage and assessment of syntactic maturity: a comparison of oral and written retellings in beginning writers. Journal of Writing research (enviado y aceptado).

Borzone de Manrique, A.M. y Granato, L. (1995). Discurso narrativo: algunos aspectos del desempeño lingüístico en niños de diferente procedencia social. Lenguas Modernas, 22,137-166.

Borzone, A.M. (2005). La resolución de anáforas en niños: incidencia de la explicitud y de la distancia. Interdisciplinaria. Revista de Psicología y Ciencias Afines. 22, 2, 155 -182 .

Borzone, A.M. y Silva, M.L. (2007). La resolución de anáforas en niños: incidencia de la causalidad implícita de los verbos. Revista Límite. Revista de Filosofía y Psicología. N ${ }^{\mathrm{o}}$ $15,100-122$.

Bronckart, J. P. (2006). Les différentes facettes de l'interactionnisme socio-discursif. Calidoscópio - Revista de Lingüística Aplicada, n. esp.: International Congress on Language and Interaction, p. 22-25.

Carroll, M. (1997). Changing place in English and German: language-specific preferences in the conceptualization of spatial relations. En E. Pederson \& J. Nuyts (eds.) Language and Conceptualization (pp.137-161). Cambridge: Cambridge Univ. Press.

Chafe, W. (1974). Language and consciousness. Language, 50,111-133.

Chafe, W. L. (1976). Givenness, contrastiveness, defmiteness, subjects, topics, and point of view. En C. N. Li (Ed.), Subject and topic (pp. 25-55). New York: Academic Press.

Gernsbacher, M.A. (2000). Language comprehension as structure building. Hillsdale, NJ: Erlbaum.

Givon, T. (1976). Topic, pronoun and grammatical agreement. In CNJ (ed) Subject and topic (pp.149188). New York: Academic Press.

Greene, S. B., McKoon, G., \& Ratcliff, R. (1992). Pronoun resolution and discourse models. Journal of Experimental Psychology: Learning, Memory, and Cognition, 18 (2), 266-283.

Hernández Pina, M. F. (1985). Teorías Psicosociolingüísticas y su aplicación a la adquisición del español como primera lengua. Madrid: Siglo XXI.

Hickmann, M. (1995). Discourse organization and the development f reference to person, space and time. En P. Fletcher \& B. MacWhinney (Eds). The Handbook of Child Language. (pp. 194-219). Oxford: Blackwell Publishers. 
Hickmann, M., Kail, M. \& Roland, F. (1995) Cohesive anaphoric relations in French children's narratives as a fuction of mutual knowledge. First Language. 15, 277 - 300.

Hudson, J.A, \& Shapiro, L.R. (1991). Children's scripts, stories and personal narratives. In A. McCabe \& C. Peterson (Eds.) Developing narrative structure (pp. 89-136). Hillsdale, NJ: Lawrence Erlbaum Associates.

Hunt, K.W. (1965). Grammatical structures written at three grade levels. Research Report 3. Urbana (IIl): NCTE.

Jisa, H. (2000). Increasing cohesion in narratives: a developmental study ofmaintaining and reintroducing subjects in French . Linguistics, 38 (3), 591-620.

Kail, M. \& Hickmann, M. (1992). French children's ability to introduce referents in narratives as function of mutual knowledge. First Language, 12, 73-94.

Kail, M. y Sánchez y López, I. (1997). Referent introductions in Spanish narratives as a function of contextual constraints: a crosslinguistic perspective. First Language, 17, $103-130$.

Karmiloff-Smith, A. (1979). A functional approach to child language: a study of determiners and reference. Cambridge: CUP.

Karmiloff-Smith, A. (1980). Psychological processes underlying pronominalization and non-pronominalization in children's connected discourse. In J. Kreiman \& E. Ojedo (Eds.) Papers from the parasession on pronouns and anaphora (pp. 231-250). Chicago: Chicago Linguistic Society.

Karmiloff-Smith A. (1981). The gramatical marking of thematic structure in the development of language production. En W. Deutsch (Ed.), The Child's Construction of Language (121-147). New-York: Academic Press.

Karmiloff-Smith, A. (1986). Some fundamental aspects of language developmental after age 5. In P. Fletcher \& M. Garman (Eds.) Language acquisition (pp. 455-474). New York: Cambridge University Press.

Lakoff, G. (1987). Women, fire and dangerous things: What categories reveal about the mind. Chicago: Univ. of Chicago Press.

Langacker, R. (1987). Foundations of Cognitive Grammar: Theoretical Prerequisites (Vol. I). Standford: Univ. Press.

Lapidus Shin, N. \& Smith Cairns, H. 2009. Subject Pronouns in Child Spanish and Continuity of Reference. En J. Collentine (Ed.) Selected Proceedings of the 11th Hispanic Linguistics Symposium, (pp. 155-164). Somerville, MA: Cascadilla Proceedings Project.

Mayer, M. (1969). Frog where are you?.New York: Dial Press.

Power, R. J.D. \& Dal Martello, M.F. (1986) The use of the definite and indefinite articles bay Italian preschool children. Journal of Child Language. 13, 145-154.

Rawson, C. (1981). Brujas. Madrid: Plaza y Jañes.

Rodríguez Fonseca, L. (1999). ¿Qué nos dicen y qué no nos dicen los índices de madurez sintáctica?. En E. E. Forastieri Braschi, , J. Cardona, H. López Morales \& A. Morales de Walters, A. (Eds.) Estudios de Lingüística hispánica: homenaje a María Vaquero (pp. 522-535).

Sautú, R. (1992). Teoría y técnicas de la medición del estatus ocupacional: Escalas objetivas y de prestigio. En Cuadernos de Ciencias Sociales 10. Buenos Aires: Instituto de Investigaciones Gino Germani, Universidad de Buenos Aires. 
Shapiro, L.R., \& Hudson, J.A. (1991). Tell me a make-believe story: Coherence and cohesion in young children's picture -elicited narratives. Developmental Psychology,27, 960-974.

Shapiro, L.R., \& Hudson, J.A. (1997). Coherence and cohesion in children's stories. En J. Costermans \& M. Fayol (Eds.) Processing interclausal relationships. Studies in the production and comprehension of text. Mahwah, N.J.: Lawrence Erlbaum Associates.

Schneider, P. \& Dubé, R. (1997). Effect of pictorial versus oral story presentation on children's use of referring expressions in retell. First Language, Vol. 17, No. 51, 283-302 (1997).

Stein, N. L. \& Glenn, C. G. (1979). An analysis of story comprehension in elementary school children. En R.O. Freedle (Ed.), New directions in discourse processing. Vol. 2: Advances in discourse processes (pp. 53-120). Norwood, NJ: Ablex.

Tomasello, M. (2003) The New Psychology of Language. Cognitive and Functional Approaches to Language Structure. London: Lawrence Erlabaum Associates Publishers.

Véliz, M. (1988). Evaluación de la madurez sintáctica en el discurso escrito, Revista de Lingüística Teórica y Aplicada, 26, 105-141.

Wigglesworth, G. (1990). Children's narrative acquisition: a study of some aspects of reference and anaphora. First Language. 10, 105-125. 